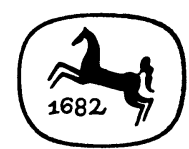

Autonomie und soziale Funktion der Kunst 
Rolf - Peter Janz

\section{Autonomie und soziale Funktion der Kunst}

Studien zur Ästhetik von Schiller und Novalis

1973

J. B. Metzlersche Verlagsbuchhandlung Stuttgart 
D 188

ISBN 978-3-476-00269-3

ISBN 978-3-476-03020-7 (eBook)

DOI 10.1007/978-3-476-03020-7

(C) Springer-Verlag GmbH Deutschland 1973

Ursprünglich erschienen bei J. B. Metzlersche Verlagsbuchhandlung und Carl Ernst Poeschel Verlag GmbH in Stuttgart 1973. 


\section{Inhalt}

Einleitung . . . . . . . . . . . . . . . . . . . 1

\section{Kunst und Sittlichkeit}

Kants \59 der Kritik der Urteilskraft . . . . . . . . . 3

Schiller, Schönheit als Freiheit in der Erscheinung . . . . . 4

Novalis, schöne Moralität und Moralität des Gewissens . . 7

Zwei Dichtungstheorien im Ofterdingen . . . . . . . 13

Die Schiller verpflichtete Poetik . . . . . . . . . . 18

Frühromantische Poetik im Monolog? . . . . . . . . . 21

II. Naturphilosophische Voraussetzungen der Ästhetik

Baader, Schelling . . . . . . . . . . . . 25

Rezeption von Tiedemanns Plotin-Darstellung . . . . . . 29

Dichtung als Medium göttlicher Offenbarung (Lehrlinge) . . 38

Zur Modernität der Sprachtheorie (Monolog) . . . . . . 43

Prinzip des Zufalls . . . . . . . . . . . . . . . 46

III. Autonomie und soziale Funktion der Kunst

Moralphilosophische und theologische Kontroversen im Ofterdingen. Kritik Kants, Fichtes, Schleiermachers . . . . . . 49

Kant, W. v. Humboldt, Goethe, K. Ph. Moritz . . . . . 55

Schiller . . . . . . . . . . . . . . . . . . 60

Novalis, Problematisierung der Kunstautonomie . . . . 67

Aktualisierung des Orpheus-Mythos . . . . . . . . . 74

IV. Frübromantische Allegorisierung

Böhme-Rezeption . . . . . . . . . . . . . . . 79

»Allegorischer Sinn im Großen« . . . . . . . . . . 81 
VI Inhalt

Affinität zur Mathematik . . . . . . . . . . . 83

Intention aufs Unendliche . . . . . . . . . . . 86

Benjamins Trauerspielbuch: Barocke und frühromantische Allegorisierung . . . . . . . . . . . . . . .

V. Ästhetische und politische Theorie

1. Novalis' Wilhelm Meister - Kritik . . . . . . . . . 98

Widerstreit von Okonomie und Poesie . . . . . . . 98

"Nobilitierter Roman« . . . . . . . . . . . . . 102

Rehabilitierung Mignons . . . . . . . . . 103

2. Politische Motive in der Darstellungsästhetik . . . . 106

F. Schlegel und Novalis, "Republikanische Verfassung" des

Romans . . . . . . . . . . . . . . . . . 106

Pathos des Naturrechts . . . . . . . . . . . 111

Klassische Form und romantisches "Bruchstück « . . . . 114

3. Historischer Gehalt der Wirkungsästhetik . . . . . 114

Kritik des Liberalismus und der Revolution . . . . . . 114

Gegenbegriff zur liberté . . . . . . . . . . . 117

Geschichtstheologische Deutung der Französischen Revolution im Europa-Aufsatz . . . . . . . . . . . . 118

Atheismus-Streit . . . . . . . . . . . . . . . 123

Apologie der Exklusivität, Macht der Kunst und politische Ohnmacht . . . . . . . . . . . . . . . . 128

Anmerkungen . . . . . . . . . . . . . . . . 133

Literaturverzeichnis . . . . . . . . . . . . 150

Personenregister . . . . . . . . . . . . . . . 155 